\title{
Summary of the Updated American Geriatrics Society/British Geriatrics Society Clinical Practice Guideline for Prevention of Falls in Older Persons
}

\author{
Developed by the Panel on Prevention of Falls in Older Persons, American Geriatrics Society and British \\ Geriatrics Society
}

The following article is a summary of the American Geriatrics Society/British Geriatrics Society Clinical Practice Guideline for Prevention of Falls in Older Persons (2010). This article provides additional discussion of the guideline process and the differences between the current guideline and the 2001 version and includes the guidelines' recommendations, algorithm, and acknowledgments. The complete guideline is published on the American Geriatrics Society's Web site (http://www.americangeriatrics.org/health_ care_professionals/clinical_practice/clinical_guidelines_recom mendations/2010/). J Am Geriatr Soc 59:148-157, 2011.

$\mathrm{T}$ he risk of falling and sustaining an injury as the result of a fall increases with age. ${ }^{1,2}$ Falls are not only associated with morbidity and mortality in the older population, but are also linked to poorer overall functioning and early admission to long-term care facilities. ${ }^{3-5}$ For older community residents, effective fall prevention has the potential to reduce serious fall-related injuries, emergency department visits, hospitalizations, nursing home placements, and functional decline. Reducing fall risk in older individuals is therefore an important public health objective. ${ }^{6}$

The Guideline for the Prevention of Falls in Older Persons was published in May 2001. ${ }^{7}$ The present publication updates the earlier guideline by evaluating evidence and analyses that have become available since 2001 and by providing revised recommendations based on these evaluations.

The development of this guideline update began by convening a panel comprising members from the previous panels and new members with substantial knowledge,

Professional Education, American Geriatrics Society, New York, New York. Address correspondence to Marianna Drootin, American Geriatrics Society, 350 Fifth Avenue, Suite 801, New York, NY 10118. E-mail: mracz@amer icangeriatrics.org

DOI: 10.1111/j.1532-5415.2010.03234.x experience, and publications in fall prevention and care of older patients. Panel members included experts in physical therapy, pharmacy, orthopedics, emergency medicine, occupational therapy, nursing, home care, and geriatric clinical practice. The literature search included meta-analyses, systematic literature reviews, randomized controlled trials (RCTs), controlled before-and-after studies, and cohort studies published between May 2001 and April 2008. (The panel reviewed the RCTs published between April 2008 and July 2009 and concluded that the additional evidence did not change the ranking of the evidence or the guideline recommendations. The negative RCTs of multifactorial interventions all involved risk factor assessment with referral without direct intervention or ensuring that the interventions were instituted.)

In addition to Medline and PubMed, the following databases were searched: Database of Abstracts of Reviews of Effectiveness, Centre for Reviews and Dissemination/ Health Technology Assessment, and the Cochrane Central Register of Controlled Trials. Interventions aimed at bone health (e.g., medications for osteoporosis) and the topics of syncope, restraints, bone protection (e.g., hip protectors), and inpatient hospital-based fall prevention, although important to fall and injury prevention, were not included in the evidence review or guideline.

Each expert panel member completed a disclosure form at the beginning of the guideline process that was shared with the entire expert panel at the start of its two expert panel meetings. Conflicts of interest in this guideline have been resolved by having the guideline independently peer reviewed and then edited by the Expert Panel Chair, who had no conflict of interest with the medications being discussed. Expert panel members who disclosed affiliations or financial interests with commercial interests involved with the products or services referred to in the guideline are listed under the disclosures section of this article.

\section{CLINICAL ALGORITHM}

The clinical algorithm describes the systematic process of decision-making and intervention that should occur in 
the management of older persons who present in a clinical setting with recurrent falls or difficulty walking or in the emergency department after an acute fall. For some interventions, outcome data were insufficient to allow evidence-based recommendations to be made, or the existing literature was ambiguous or conflicting. In these cases, the panel made recommendations based on consensus after intensive discussion.

\section{Grading the Strength of Recommendations}

A standardized format based on an evidence rating system used by the U.S. Preventative Services Task Force was used to critically analyze the literature and grade the evidence for this document. ${ }^{8}$

Based on overall quality of evidence and magnitude of benefit for each intervention, the committee assigned a rating of $\mathrm{A}, \mathrm{B}, \mathrm{C}$, or $\mathrm{D}$ to each recommendation $(\mathrm{A}=\mathrm{a}$ strong recommendation that physicians provide the intervention to eligible patients, $\mathrm{B}=\mathrm{a}$ recommendation that clinicians provide this intervention to eligible patients, $\mathrm{C}=$ that no recommendation for or against the routine provision of the intervention can be made, and $\mathrm{D}=$ that the panel recommends against routinely providing the intervention to asymptomatic patients). If evidence was insufficient to come to a decision for or against the intervention, the panel assigned a rating of $\mathrm{I}$.

\section{Changes Since the 2001 Guidelines}

\section{Assessments}

The 2010 guidelines, although recommending a multifactorial fall risk assessment for all older adults who present with a fall or who have gait and balance problems, also calls for a multifactorial falls risk assessment for individuals who simply report difficulties with gait or balance. A falls risk assessment is not considered necessary for older persons reporting only a single fall without reported or demonstrated difficulty or unsteadiness.

The history of fall circumstances is more specific in the 2010 guidelines, including questions about frequency of falling, symptoms at time of fall, and injuries from fall.

New specific recommendations for assessment include examination of the feet and footwear, functional assessment (assessment of activity of daily living skills, including use of adaptive equipment and mobility aids, as appropriate); assessment of the individual's perceived functional ability and fear related to falling; and environmental assessment, including home safety.

\section{Interventions}

New recommendations specify that direct interventions adjusted for the identified risk factors, performed by the health professionals who performed the assessment or other healthcare professionals referred by them must follow the multifactorial fall risk assessment.

All multifactorial interventions for community-residing older people should have an exercise component. Exercise recommendations in the 2010 guidelines specify programs that include balance, gait, and strength training, such as tai chi or physical therapy, in group programs or as individual programs at home. The 2001 guidelines were unable to recommend tai chi, because inadequate data were available at that time. Endurance and flexibility training are supported but not as sole components of a program. Current data support exercise programs only for communitydwelling older persons, in contrast to the earlier guidelines, which recommended long-term exercise and balance training for all older people who have had recurrent falls.

A healthcare professional should perform environmental adaptation or modification, not only environmental assessment, as part of a multifactorial fall risk assessment and intervention for all older persons who have fallen or who have risk factors for falls. The intervention should include mitigation of fall risk factors identified in the home and evaluation and interventions to promote safe performance of daily activities.

Cataract surgery on the first eye should be expedited in older persons in which the surgery is indicated; however, the new guidelines recommend against vision assessment or intervention as an individual approach outside of a multifactorial assessment and intervention strategy.

Medication reduction or withdrawal is stressed for all older people, not only for those taking four or more medications, as in the earlier guidelines.

Assessment and treatment of postural hypotension should be included as part of a multifactorial intervention approach.

Dual-chamber cardiac pacing should be considered for older persons with cardioinhibitory carotid sinus hypersensitivity who experience unexplained recurrent falls.

Vitamin D (800 IU) is recommended as a daily supplement for all older adults at risk of falls. Vitamin D is also recommended for all older adults with known vitamin D deficiency and should be considered for those suspected of having vitamin $\mathrm{D}$ deficiency. There is strong evidence for vitamin $\mathrm{D}$ supplementation $(800 \mathrm{IU} / \mathrm{d})$ in patients residing in long-term care who have known vitamin $\mathrm{D}$ deficiency; vitamin D supplementation should also be considered for those with problems of gait or balance or who are otherwise at risk for falls residing in long-term care.

No specific recommendations are made for or against assistive devices, alarms, or hip protectors.

For older persons with cognitive impairment, there is insufficient evidence for supporting any recommendations to reduce fall risk.

\section{SCREENING AND ASSESSMENT}

Further explanation of the basis of the clinical algorithm is provided below (Figure 1).

Annotation A: Older Adult Encounters with Healthcare Provider. This guideline algorithm is to be used in the clinical setting for assessment and intervention to reduce falls in community-residing older persons $(\geq 65)$. The guideline algorithm is not intended to address fall injuries per se or falls that occur in the hospital.

Annotation B: Screen for Falls or Risk for Falling. The screening for falls and risk for falling is aimed at preventing or reducing fall risk. Any positive answer to the screening questions puts the person screened in a high-risk group that warrants further evaluation. All older adults who are under the care of a health professional (or their caregivers) should be asked at least once a year about falls, frequency of falling, and difficulties in gait or balance. 
Prevention of Falls in Older Persons Living in the Community

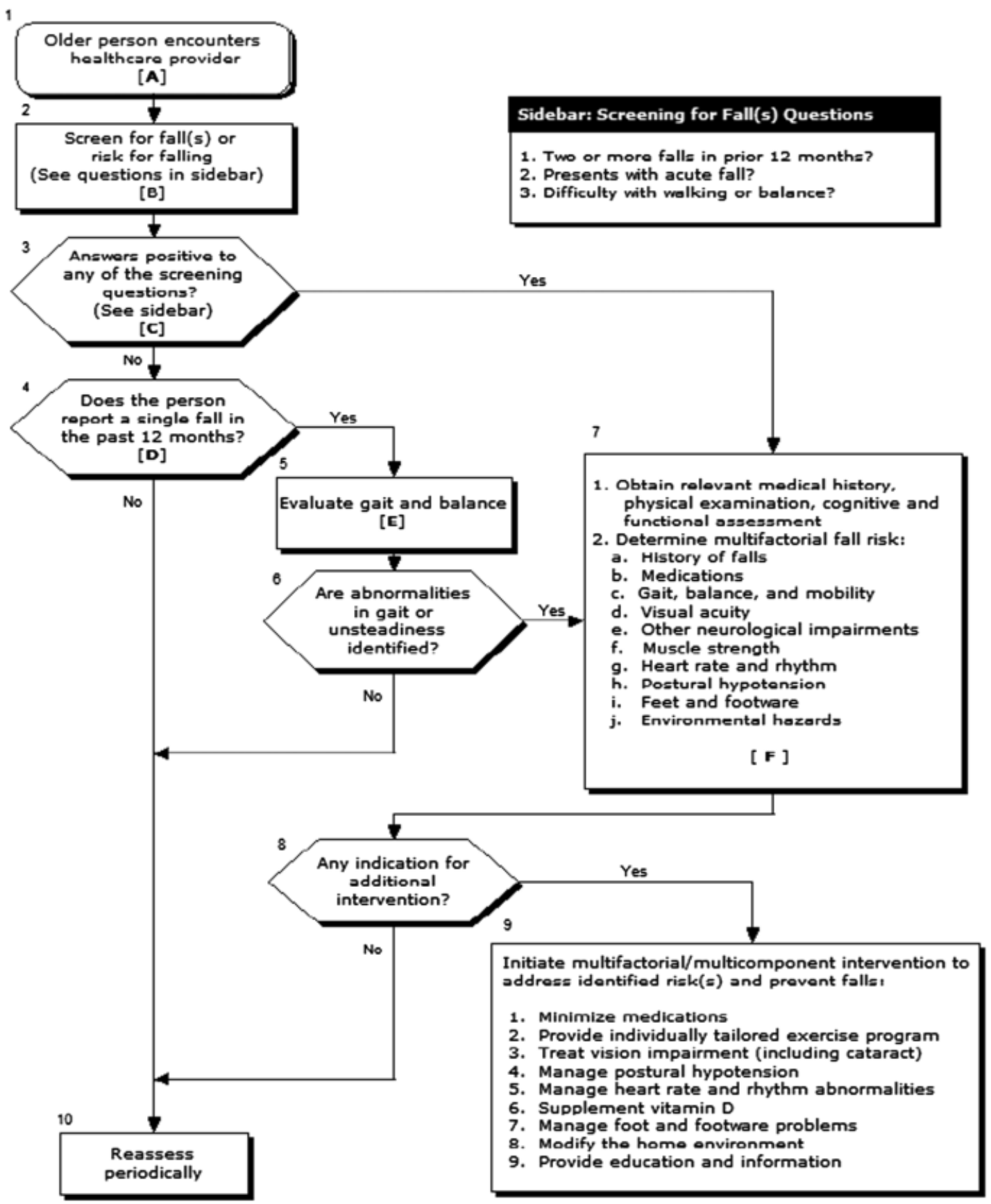

Figure 1. Algorithm and annotations.

Annotation C: Screen Positive for Falls or Risk for Falling. Persons at higher risk of falling, identified by screening, should be assessed for known risk factors. A multifactorial fall risk assessment should be performed for community-dwelling older persons who report recurrent $(\geq 2)$ falls, report difficulties with gait or balance, or seek medical attention or present to the emergency department because of a fall.

Annotation D: Report of a Single Fall in the Past 12 Months. A (first) single fall may indicate difficulties or un- steadiness in walking or standing. In older individuals, a fall may be a sign of problems in gait or balance that was not present in the past.

Annotation E: Evaluation of Gait and Balance. Gait and balance deficits should be evaluated in older individuals reporting a single fall as a screen for identifying individuals who may benefit from a multifactorial fall risk assessment. For persons who screen positive for falls or fall risk, evaluation of balance and gait should be part of the multifactorial fall risk assessment. Frequently used tests of gait or 
balance include the Get Up and Go Test; ${ }^{9}$ Timed Up and Go Test,${ }^{10}$ the Berg Balance Scale, ${ }^{11}$ and the PerformanceOriented Mobility Assessment. ${ }^{5,12}$

Annotation F: Determination of Multifactorial Fall Risk. A multifactorial fall risk assessment can reveal the factors that put an older adult at risk of falling and can help identify the most appropriate interventions. A multifactorial fall risk assessment followed by intervention to modify any identified risks is a highly effective strategy to reduce falls and the risk of falling in older persons.

\section{INTERVENTIONS}

\section{Initiation of Multifactorial or Multicomponent Interventions to Address Identified Risk(s) and Prevent Falls}

Two methods for reducing multiple risk factors have been tested in clinical trials. The first method, termed "multicomponent intervention" in this guideline, refers to a set of interventions offered to all participants in a program that addresses more than one intervention category. This method has been used most often in long-term care settings. In the second method, called "multifactorial intervention," participants are offered only the adjusted subset of interventions that target the risk factors that have been identified through a fall risk factor assessment. This targeted or customized approach has been implemented primarily in community-dwelling older persons. ${ }^{13}$ Because of the great heterogeneity among the designs of the multifactorial and multicomponent studies, the panel chose to include trials with multifactorial or multicomponent approaches regardless of dimensions.

Most of the components included in multicomponent or customized multifactorial interventions can be described under the broad headings of exercise and physical activity, medical assessment and management, medication adjustment, environmental modification, and education. A significant body of evidence, including two meta-analyses, supported the multifactorial or multicomponent approach to interventions designed to prevent falls in older persons. ${ }^{14-35}$ Risk factor assessment without direct intervention into the identified risk factors does not appear to be effective. $^{25-28,32,33,36-38}$ Attention to the following domains are particularly effective: environmental adaptation; balance, transfer, strength, and gait training; reduction in medications, particularly psychoactive medications; and management of visual deficits, postural hypotension, and other cardiovascular and medical problems. The effectiveness of visual interventions other than first cataract surgery is less clear.

\section{Minimization of Medications}

Medications have consistently been associated with risk of falls. The strongest risk associations occur with psychotropic medications and polypharmacy. ${ }^{39-41}$ The strongest evidence supports withdrawal of psychotropic medication, as a single intervention and as a component of multifactorial and multicomponent intervention. If discontinuation of a particular high-risk medication is not possible because of medical conditions, dose reduction should be considered. Although some clinicians believe that selective serotonin reuptake inhibitors (SSRIs) are generally safer to use in older adults than tricyclic antidepressants, in terms of fall prevention, evidence is building that SSRIs increase fall risk as much as the older tricyclic antidepressants. Reduction of psychotropic medication as a single intervention has been found to reduce fall rate, ${ }^{14}$ whereas assessment, adjustment, and discontinuation of medication regimens as part of a multifactorial intervention, has also been found to be effective in reducing falls. ${ }^{19-21,23,34,42}$

\section{Initiation of a Customized Exercise Program}

A range of exercise types have been investigated, both individual and group exercises that can be used in isolation or in combination including balance exercises, strength training, flexibility (muscle and joint stretching techniques), tai chi, and cardiovascular, endurance, and fitness training. Because a large body of evidence supports the recommendation that exercise, in the form of resistance (strength) training and balance, gait, and coordination training, is effective in reducing falls, the panel concluded that exercise, in the form of strength training and balance, gait, and coordination training, ${ }^{15,16,43}$ should be included as part of a multifactorial or multicomponent intervention to prevent falls in older persons and may be considered as a single intervention. In most positive trials, the exercise program was longer than 12 weeks (1-3 times per week) with variable intensity.

Exercise may be more effective when applied alongside other interventions. Exercise programs were associated with fewer falls in multifactorial and multicomponent studies. ${ }^{14,19,21,24,31,35}$ Exercise programs should be initiated with caution because some studies have shown that exercise may increase the rate of falls in persons with limited mobility who are not accustomed to physical activity. Some trials that included balance training ${ }^{43-48}$ as part of the intervention showed significant reduction in falls in addition to other benefits in gait, balance, and reduced fear of falling.

\section{Treating Vision Impairment}

Aging is often associated with changes in visual acuity, development of cataracts, macular degeneration, glaucoma, and other conditions that would suggest an effect on risk of falling. If patients report problems or concerns, their vision should be formally assessed, and any remediable visual abnormalities should be treated, particularly cataracts.

A systematic review ${ }^{15}$ found no evidence that referral for correction of vision in community-dwelling older people was effective in reducing the number of people falling, although this conclusion was based on a single RCT. ${ }^{24}$ Two RCTs assessing the effect of a cataract operation and waiting list time for surgery showed a lower rate of falling for immediate surgery than delayed surgery. ${ }^{49,50}$ Three studies that included vision correction as part of a multifactorial assessment and intervention had mixed results. ${ }^{21,24,51} \mathrm{It}$ remains unclear whether vision is an essential component of multifactorial intervention. One randomized trial examining a vision assessment and follow-up intervention alone indicated that vision assessment and intervention increased risk of falling. This may be related to the effects of adjusting to new glasses. ${ }^{52}$ 


\section{Managing Postural Hypotension}

Postural hypotension is associated with greater risk of falls. It most commonly occurs as a result of dehydration, concomitant medications, and autonomic neuropathy. Many multifactorial fall prevention programs that have shown benefit for fall prevention have included medication reduction and simplification to modify postural blood pressure, as well as specific strategies such as hydration, elastic stockings, abdominal binders, and medications (e.g., fludrocortisone and midodrine). Managing postural hypotension should be included as a component of multifactorial intervention in community-living older persons.

Three RCTs have demonstrated a benefit associated with treatment of postural hypotension in addition to interventions such as medication reduction, optimization of fluids, and behavioral intervention. ${ }^{19,20,23}$

\section{Managing Heart Rate and Rhythm Abnormalities}

The most common cardiovascular disorders associated with falls are carotid sinus hypersensitivity, vasovagal syndrome, bradyarrhythmias (e.g., sick sinus syndrome and atrioventricular block), and tachyarrhythmias. Two mechanisms have been proposed. The first is transient loss of consciousness with amnesia in which the patient has no recollection of short episodes of syncope; this has been reported with postural hypotension and carotid sinus hypersensitivity. ${ }^{53}$ Given that up to $70 \%$ of falls in older persons are not witnessed, these patients may present with a report of a fall rather than syncope. A second proposed mechanism is that of transient hypotensive episodes, due to primary hypotension or hypotension secondary to arrhythmias, which cause a person with comorbid gait and balance instability to lose balance and fall without frank syncope. Cardiac pacing treats bradycardia. One RCT of cardiac pacing in community-dwelling older people who had recurrent unexplained falls, reported a significant reduction in fall rates at 12month follow-up. ${ }^{54}$ For the subset of older adults who meet the necessary diagnostic criteria, dual-chamber cardiac pacing for bradyarrhythmias (including carotid sinus hypersensitivity and conduction disorders) and treatment of tachyarrhythmia are components of a multifactorial intervention designed to reduce the risk for falls.

\section{Vitamin D Supplementation}

Vitamin D deficiency is common in older people and when present impairs muscle strength and possibly neuromuscular function. Several recent meta-analyses and RCTs have shown a beneficial effect of vitamin D supplementation in fall prevention distinct from its effect on bone health. ${ }^{55-60}$ Some of these trials have also shown benefit even in older persons with normal serum vitamin D levels. Given the low number needed to treat of 15 and the evidence of significant fall risk reduction, as well as the fact that vitamin D is safe and inexpensive, older persons with suspected vitamin D deficiency should be routinely offered supplementation to reduce fall risk. Moreover, vitamin D supplementation at appropriate levels should also be considered for all older adults.

\section{Managing Foot and Footwear Problems}

Foot problems are common in older people and are associated with impaired balance and performance in tests of function. Serious foot problems (moderate or severe bunions, toe deformities, ulcers or deformed nails) predispose older adults to falls. ${ }^{12}$ Also, foot position awareness is significantly poorer in older persons.

The type and condition of footwear may also contribute to the risk of falling. Footwear that fits poorly, has worn soles, has high heels, or is not laced or buckled when worn has been associated with a higher risk of falling. ${ }^{61}$ Shoes with low heel height and high surface contact area may reduce the risk for falling. ${ }^{62-65}$ Most of the studies that implemented a multifactorial assessment for reducing the risk of falling, included a foot assessment coupled with advice or referral for appropriate treatment, if any foot problems were identified. ${ }^{27,29,66,67}$ (See Multifactorial Intervention.) Assessment and recommendations for use of appropriate shoes were also included in home hazards studies. ${ }^{51,68}$ One small study found that antislip shoe devices were effective in reducing outdoor falls in slippery conditions. ${ }^{69}$

\section{Modification of the Home Environment}

Environmental hazards are any objects or circumstances in the environment that increase an individual's risk of falling and may be within the home and grounds (commonly termed home falls hazards) or away from the home (public falls hazards). Identification and mitigation of environmental hazards has been a recommended component of many successful fall prevention programs. The panel concluded that screening of the home environment with follow-up for any needed modifications by a healthcare professional is an effective targeted intervention for people with a previous fall history or other fall risk factors. Programs include home hazard assessments by trained individuals, removal or modification of identified hazards, installation of safety devices such as handrails on stairs and grab bars on bathrooms, and improvements in lighting.

Although evidence supporting the use of home environment assessment and intervention alone as a strategy to reduce falls in community-dwelling older adults is mixed (not supportive, ${ }^{24,70}$ supportive ${ }^{71}$ ), evidence for home environment assessment and intervention as part of a multifactorial fall prevention program is strong. ${ }^{19-21,23-27,31,32,35-37,72,73}$ Further insights regarding effectiveness of the interventions are gained through the meta-analysis. ${ }^{15}$ One RCT found particular benefit in highrisk frail older subjects with a falls history. ${ }^{30}$

\section{Providing Education and Information}

All fall prevention programs include educational and health promotion components. Education of patient and caregiver can be considered as primary and secondary prevention measures and is also important for implementation and sustained use of fall prevention strategies. Many effective programs include opportunities for older adults to access fall prevention resources (e.g., durable medical equipment, local exercise programs) and to take specific actions that maintain or improve health or build fall prevention skills 
(e.g., transferring safely into the bathtub, learning how to use mobility devices).

Specific educational goals may be considered fundamental components of fall prevention interventions (e.g., increasing older adults' activity level, improving ability to identify and mitigate fall hazards in the home, and providing information to make good choices about footwear); however, there is little evidence to determine the incremental benefit of such educational input on fall rates in a multicomponent intervention $27,30,37,70,74$ or as a sole fall prevention intervention. ${ }^{31,66,67,75}$ In one RCT of a cognitive-behavioral falls prevention program, "Stepping On," that was part of a multicomponent community-based program, falls were $31 \%$ lower in the intervention group. ${ }^{21}$

\section{OLDER PERSONS IN LONG-TERM CARE FACILITIES}

Falling is more frequent in ambulatory residents of longterm care facilities than in older persons residing in the community. Approximately half of ambulatory long-term care residents experience at least one fall each year.

Trials in long-term care facilities have addressed single interventions administered alone and multiple interventions administered together. ${ }^{76}$ Single interventions include use of hip protectors, fall alarm devices, removal of physical restraints, medication review, and supplementation with calcium and vitamin D. Many factors, such as variation in type and severity of disability of residents, differences in structure of care and terminology used to describe facilities, lack of information about the cognitive or physical functioning of participants, and insufficient description of the interventions, complicate interpretation of the evidence from RCTs in the long-term care setting.

\section{Multicomponent Interventions}

These are the most commonly studied strategies in longterm care settings. "Targeted" or "customized" multifactorial interventions have also been tested. Staff training and feedback, environmental adaptations, balance and gait training, strength training, training in the use of appropriate assistive devices, and decrease in psychotropic medications are interventions that have frequently been included in multicomponent intervention and multifactorial trials in this setting. The effectiveness of multicomponent studies in reducing falls in long-term care is uncertain. Three ${ }^{77-79}$ of the eight trials of multiple component interventions were effective in reducing fall risk; the others found no significant effects. ${ }^{38,51,80-82}$ Medication review as part of a multicomponent intervention has provided inconclusive evidence as to whether medication assessment, adjustment, and discontinuation results in fewer falls. ${ }^{51,78,79}$

Environmental components were included in six of the eight studies of multicomponent interventions in the longterm care setting, of which three studies were ineffective $^{51,78,80}$ and three effective. ${ }^{76,78,83}$ Two RCTs incorporating multifactorial interventions and achieving significant reductions in falls incorporated environmental assessment and modifications. ${ }^{77,78}$ No data were reported on the effectiveness of the environmental modifications alone.

The education of long-term care staff has resulted in mixed results but has probably contributed to reduction of falls in some large studies. Some evidence supports the effectiveness of healthcare team training in awareness and prevention strategies, although several multifactorial studies failed to show significant reduction in falls.

\section{Exercise}

Although exercise may provide certain benefits for long-term care residents, particularly in terms of qualityof-life parameters, confounding variables (differences in frailty levels, cognitive function, prior falls history, small size of many studies) mitigate against clearly defined conclusions. ${ }^{81,84-89}$ Some studies found a greater risk of falls with exercise. ${ }^{85}$ There are currently no clinical RCTs to recommend, for or against, the use of individually customized exercise programs to prevent falls in long-term care settings.

\section{Vitamin D}

Studies from meta-analyses and recent RCTs support the use of combined calcium and vitamin D3 supplementation to reduce fracture rates in older people in long-term care. ${ }^{55,90,91}$

\section{OLDER PERSONS WITH COGNITIVE IMPAIRMENT}

Older people with cognitive impairment and dementia are at greater risk for falls, with an annual incidence of approximately $60 \% .{ }^{12,92}$ Cognitive impairment is an independent risk factor for falls. Mobility problems experienced with dementia are associated with falls, fractures, and admission to long-term care.

At this time, there is insufficient evidence to recommend, for or against, single or multifactorial interventions in community-living older adults with known cognitive impairment. ${ }^{13,82,83}$ The only study that specifically investigated cognitive impairment in the community demonstrated lack of efficacy. ${ }^{82}$

Physical activity was evaluated for its effectiveness in reducing falls in a systematic review of 11 RCTs of cognitively impaired subjects. The investigators observed only limited effectiveness of physical training or exercise in reducing fall risk. ${ }^{13}$

A study of education as part of a multicomponent intervention program that included staff education, drug review, environmental adjustment, exercise, aids, hip protectors, and postfall problem-solving conferences observed that education was associated with a significant intervention effect on falls in the group with higher Mini-Mental State Examination scores but not in the group with lower scores. ${ }^{83}$

The effectiveness of a customized multicomponent intervention after multifactorial clinical assessment was investigated in older patients with cognitive impairment and dementia presenting to the emergency department after a fall. ${ }^{82}$ Interventions included optical correction, medical assessment, physiotherapy, occupational therapy, and foot care. No significant difference between the intervention and control groups in fall risk was found. 


\section{RECOMMENDATIONS: SCREENING AND ASSESSMENT}

All older individuals should be asked whether they have fallen (in the past year).

1. An older person who reports a fall should be asked about the frequency and circumstances of the fall(s).

2. Older individuals should be asked whether they experience difficulties with walking or balance.

3. Older persons who present for medical attention because of a fall, report recurrent falls in the past year, or report difficulties in walking or balance (with or without activity curtailment) should have a multifactorial fall risk assessment.

4. Older persons who cannot perform or perform poorly on a standardized gait and balance test should be given a multifactorial fall risk assessment.

5. Older persons who report a single fall in the past year should be evaluated for gait and balance.

6. Older persons who have fallen should have an assessment of gait and balance using one of the available evaluations.

7. Older persons who have difficulty or demonstrate unsteadiness during the evaluation require a multifactorial fall risk assessment.

8. Older persons reporting only a single fall in the past year and reporting or demonstrating no difficulty or unsteadiness during the evaluation do not require a fall risk assessment.

9. A clinician (or clinicians) with appropriate skills and training should perform the multifactorial fall risk assessment.

10. The multifactorial fall risk assessment should include the following.

\section{A. Focused History}

(i) History of falls: detailed description of the circumstances of the fall(s), frequency, symptoms at time of fall, injuries, other consequences

(ii) Medication review: all prescribed and over-the-counter medications with dosages

(iii) History of relevant risk factors: acute or chronic medical problems (e.g., osteoporosis, urinary incontinence, cardiovascular disease)

\section{B. Physical Examination}

(i) Detailed assessment of gait, balance, and mobility levels and lower extremity joint function

(ii) Neurological function: cognitive evaluation, lower extremity peripheral nerves, proprioception, reflexes, tests of cortical, extrapyramidal and cerebellar function

(iii) Muscle strength (lower extremities)

(iv) Cardiovascular status, heart rate and rhythm, postural pulse and postural blood pressure, and if appropriate heart rate and blood pressure responses to carotid sinus stimulation

(v) Assessment of visual acuity

(vi) Examination of the feet and footwear

\section{Functional Assessment}

(i) Assessment of activity of daily living skills, including use of adaptive equipment and mobility aids, as appropriate (ii) Assessment of the individual's perceived functional ability and fear related to falling

(assessment of current activity levels with attention to the extent to which concerns about falling are protective (appropriate given abilities) or contributing to deconditioning or compromised quality of life (individual is curtailing involvement in activities he or she is safely able to perform due to fear of falling))

\section{Environmental Assessment}

\section{INTERVENTIONS: OLDER PERSONS LIVING IN THE COMMUNITY}

12. Direct interventions customized to the identified risk factors, coupled with an appropriate exercise program should follow the multifactorial fall risk assessment. [A]

13. A strategy to reduce the risk of falls should include multifactorial assessment of known fall risk factors and management of the risk factors identified. [A]

14. The components most commonly included in efficacious interventions were:

(a) Adaptation or modification of home environment [A]

(b) Withdrawal or minimization of psychoactive medications [B]

(c) Withdrawal or minimization of other medications [C]

(d) Management of postural hypotension [C]

(e) Management of foot problems and footwear [C]

(f) Exercise, particularly balance, strength, and gait training $[\mathrm{A}]$

15. All older adults who are at risk of falling should be offered an exercise program incorporating balance, gait, and strength training. Flexibility and endurance training should also be offered but not as sole components of the program. [A]

16. Multifactorial or multicomponent interventions should include an education component complementing and addressing issues specific to the intervention being provided, customized to individual cognitive function and language. [C]

17. The health professional or team conducting the fall risk assessment should directly implement the interventions or ensure that other qualified healthcare professionals conduct the interventions. [A]

18. Psychoactive medications (e.g., sedative hypnotics, anxiolytics, antidepressants) and antipsychotics (e.g., new antidepressants or antipsychotics) should be minimized or withdrawn, with appropriate tapering if indicated. [B]

19. A reduction in the total number of medications or dose of individual medications should be pursued. All medications should be reviewed and minimized or withdrawn. [B]

20. Exercise should be included as a component of multifactorial interventions for fall prevention in community-residing older persons. [A]

21. An exercise program that targets strength, gait, and balance, such as tai chi or physical therapy, is recommended as an effective intervention to reduce falls. [A] 
22. Exercise may be performed in groups or as individual (home) exercises because both are effective in preventing falls. [B]

23. Exercise programs should take into account the physical capabilities and health profile of the older person (i.e., be customized) and be prescribed by qualified health professionals or fitness instructors. [I]

24. The exercise program should include regular review, progression, and adjustment of the exercise prescription as appropriate. [I]

25. In older women in whom cataract surgery is indicated, surgery should be expedited because it reduces the risk of falling. [B]

26. There is insufficient evidence to recommend for or against the inclusion of vision interventions within multifactorial fall prevention interventions. [I]

27. There is insufficient evidence to recommend vision assessment and intervention as a single intervention for the purpose of reducing falls. [D]

28. An older person should be advised not to wear multifocal lenses while walking, particularly on stairs. [C]

29. Assessment and treatment of postural hypotension should be included as components of multifactorial interventions to prevent falls in older persons. [B]

30. Dual-chamber cardiac pacing should be considered for older persons with cardioinhibitory carotid sinus hypersensitivity who experience unexplained recurrent falls. [B]

31. Vitamin D supplements of at least $800 \mathrm{IU}$ per day should be provided to older persons with proven vitamin $\mathrm{D}$ deficiency. [A]

32. Vitamin D supplements of at least $800 \mathrm{IU}$ per day should be considered for people with suspected vitamin D deficiency or who are otherwise at high risk for falls. [B]

33. Identification of foot problems and appropriate treatment should be included in multifactorial fall risk assessments and interventions for older persons living in the community. [C]

34. Older people should be advised that walking with shoes of low heel height and high surface contact area may reduce the risk of falls. [C]

35. Home environment assessment and intervention performed by a healthcare professional should be included in a multifactorial assessment and intervention for older persons who have fallen or who have risk factors for falling. [A]

36. The intervention should include mitigation of identified hazards in the home and evaluation and interventions to promote the safe performance of daily activities. [A]

37. Education and information programs should be considered part of a multifactorial intervention for older persons living in the community. [C]

38. Education should not be provided as a single intervention to reduce falls in older persons living in the community. [D]

39. There is insufficient evidence to recommend for or against multifactorial or multicomponent interventions in long-term care settings. [C]

40. Exercise programs should be considered for a variety of benefits to reduce falls in older persons living in longterm care settings (with caution regarding risk of in- jury), although their effect on fall risk in these settings is unproven. (C)

41. Vitamin D supplements of at least $800 \mathrm{IU}$ per day should be provided to older persons residing in longterm care settings with proven or suspected vitamin $\mathrm{D}$ insufficiency. [A]

42. Vitamin D supplements of at least $800 \mathrm{IU}$ per day should be considered in older persons residing in longterm care settings who have abnormal gait or balance or who are otherwise at high risk for falls. [B]

43. There is insufficient evidence to recommend for or against multifactorial or single interventions to prevent falls in older persons with known dementia living in the community or in long-term care facilities. [I]

\section{ACKNOWLEDGMENTS}

\section{Panel members and affiliations}

The American Geriatrics Society and British Geriatrics Society Panel on the Clinical Practice Guideline for the Prevention of Falls in Older Persons includes: Rose Anne M. Kenny, MD, (Chair), Trinity College and St James Hospital, Dublin, Ireland; Laurence Z. Rubenstein, MD, MPH (Chair), UCLA School of Medicine, Los Angeles, CA; Mary E. Tinetti, MD (Chair), Yale University School of Medicine, New Haven, CT; Kathryn Brewer, PT, MEd, GCS, Mayo Clinic Hospital, Phoenix, AZ; Kathleen A. Cameron, RPh, MPH, American Society of Consultant Pharmacists Research and Education Foundation, Alexandria, VA; Elizabeth A. Capezuti, PhD, RN, New York University College of Nursing, New York, NY; David P. John, MD, Caritas Carney Hospital, Dorchester, MA; Sallie Lamb, DPhil (Oxon), MSc, MCSP, SRP, University of Warwick, Coventry, UK; Finbarr Martin, MD, MSc, FRCP, St Thomas' Hospital, London, England; Paul H. Rockey, MD, MPH, American Medical Association, Chicago, IL; Mary Suther, National Association for Home Care and Hospice, Dallas, TX; Elizabeth Walker Peterson, MPH, OTR/L, University of Illinois, Chicago, IL.

The following organizations endorsed the Clinical Practice Guideline for the Prevention of Falls in Older Persons: The American College of Emergency Physicians, the American Medical Association, the American Occupational Therapy Association, and the American Physical Therapy Association.

Oded Susskind, MPH, Medical Education Consultant, Brookline, Massachusetts, provided guideline development facilitation. Sue Radcliff, Independent Researcher, Denver, Colorado, provided research services. Katherine Addleman, $\mathrm{PhD}$, provided editorial services. Marianna Drootin, Elvy Ickowicz, MPH, and Nancy Lundebjerg, MPA, American Geriatrics Society, New York, New York, provided additional research and administrative support.

Peer Review: The following organizations with special interest and expertise in the prevention of falls in older persons provided peer review of a preliminary draft of this guideline: American Academy of Family Physicians, American Academy of Home Care Physicians, American Academy of Ophthalmology, American Academy of Otolaryngology, American Academy of Physical Medicine and Rehabilitation, American College of Emergency Physicians, American College of Physicians, American Medical 
Association, American Occupational Therapy Association, American Physical Therapy Association, British Association for Emergency Medicine, Chartered Society of Physiotherapists College of Occupational Therapists (UK), National Association for Home Care and Hospice, Gerontological Advanced Practice Nurses Association, Royal Pharmaceutical Society of Great Britain, Society for Academic Emergency Medicine, and the Society for General Internal Medicine.

Financial Disclosure: Dr. Tinetti, Dr. Rubenstein, Dr. Kenny, Dr. Lamb, Dr. Rockey, Ms. Brewer, Ms. Peterson, and $\mathrm{Mr}$. Susskind report no financial relationships with relevant commercial entities. Ms. Cameron holds shares in Johnson \& Johnson. Ms. Suther holds shares in various pharmaceutical companies. Dr. Capezuti is a board member of Medco Health Solutions, Inc. Dr. John receives grants from the American College of Emergency Physicians. Dr. Martin has received hospitality, but no fees from Pfizer, Orion, and Pharmacia.

\section{REFERENCES}

1. Campbell AJ, Spears GF, Borrie MJ. Examination by logistic regression modeling the variables which increase the relative risk of elderly women falling compared to elderly men. J Clin Epidemiol 1990;43:1415-1420.

2. Rubenstein LZ, Powers C. The epidemiology of falls and syncope. Clin Geriatr Med 2002;18:141-158.

3. Brown AP. Reducing falls in elderly people: A review of exercise interventions. Physiother Theory Pract 1999;15:59-68.

4. Rubenstein LZ, Josephson KR, Robbins AS. Falls in the nursing home. Ann Intern Med 1994;121:442-451.

5. Tinetti ME. Performance-oriented assessment of mobility problems in elderly patients. J Am Geriatr Soc 1986;34:119-126.

6. Sattin RW. Falls among older persons: A public health perspective. Annu Rev Public Health 1992;13:489-508.

7. Guideline for the prevention of falls in older persons. American Geriatrics Society, British Geriatrics Society, and American Academy of Orthopaedic Surgeons Panel on Falls Prevention.. J Am Geriatr Soc 2001;49:664-672.

8. Harris RP, Helfand M, Woolf SH et al. Methods Work Group, Third US Preventive Services Task Force. Current methods of the US Preventive Services Task Force: A review of the process. Am J Prev Med 2001;20(3 Suppl):21-35.

9. Mathias S, Nayak US, Isaacs B. Balance in elderly patients: The "Get-Up and Go" test. Arch Phys Med Rehab 1986;67:387-389.

10. Podsiadlo D, Richardson S. The timed "Up \& Go": A test of basic functional mobility for frail elderly persons. J Am Geriatr Soc 1991;39:142-148.

11. Berg K, Wood-Dauphinee SL, Williams JI et al. Measuring balance in the elderly; preliminary development of an instrument. Physiother Canada 1989;41:304-11.

12. Tinetti ME, Speechley M, Ginter SF. Risk factors for falls among elderly persons living in the community. N Engl J Med 1988;319:1701-1707.

13. Hauer K, Lamb SE, Jorstad EC et al. PROFANE-Group. Systematic review of definitions and methods of measuring falls in randomised controlled fall prevention trials. Age Ageing 2006;35:5-10.

14. Campbell AJ, Robertson MC, Gardner MM et al. Psychotropic medication withdrawal and a home-based exercise program to prevent falls: A randomized controlled trial. J Am Geriatr Soc 1999;39:142-148.

15. Gillespie LD, Gillespie WJ, Robertson MC et al. Interventions for preventing falls in elderly people. Cochrane Database Syst Rev 2003;4:CD000340.

16. Chang JT, Morton SC, Rubenstein LZ et al. Interventions for the prevention of falls in older adults: Systematic review and meta-analysis of randomized clinical trials. BMJ 2004;328:680-683.

17. Hill K. Review: Intrinsic and environmental risk-factor modification reduces falls in elderly persons. ACP J Club 2002;137:9.

18. Weatherall M. Prevention of falls and fall-related fractures in communitydwelling older adults: A meta-analysis of estimates of effectiveness based on recent guidelines. Intern Med J 2004;34:102-108.

19. Tinetti ME, Baker DI, McAvay G et al. A multifactorial intervention to reduce the risk of falling among elderly people living in the community. N Engl J Med 1994;331:821-827.

20. Close J, Ellis M, Hooper R et al. Prevention of falls in the elderly trial (PROFET): A randomized controlled trial. Lancet 1999;353:93-97.
21. Clemson L, Cumming R, Kendig $\mathrm{H}$ et al. The effectiveness of a communitybased program for reducing the incidence of falls in the elderly: A randomized trial. J Am Geriatr Soc 2004;52:1487-1494.

22. Coleman EA, Grothaus LC, Sandhu N et al. Chronic care clinics: A randomized controlled trial of a new model of primary care for frail older adults. J Am Geriatr Soc 1999;47:775-783.

23. Davison J, Brady S, Kenny RA. 24-hour ambulatory electrocardiographic monitoring is unhelpful in the investigation of older persons with recurrent falls. Age Ageing 2005;34:382-386.

24. Day L, Fildes B, Gordon I et al. Randomised factorial trial of falls prevention among older people living in their homes. BMJ 2002;325:128-133.

25. Gallagher EM, Brunt H. Head over heels: Impact of a health promotion program to reduce falls in the elderly. Can J Aging 1996;15:84-96.

26. Hogan DB, MacDonald FA, Betts J et al. A randomized controlled trial of a community-based consultation service to prevent falls. Can Med Assoc J 2001;165:537-543.

27. Lightbody E, Watkins C, Leathley $M$ et al. Evaluation of a nurse-led falls prevention programme versus usual care: A randomized controlled trial. Age Ageing 2002;31:203-210.

28. Newbury JW, Marley JE, Beilby JJ. A randomised controlled trial of the outcome of health assessment of people aged 75 years and over. Med J Aust 2001;175:104-107.

29. Davison J, Bond J, Dawson P et al. Patients with recurrent falls attending accident $\&$ emergency benefit from multifactorial intervention-a randomised controlled trial. Age Ageing 2005;34:162-168.

30. Nikolaus T, Bach M. Preventing falls in community-dwelling frail older people using a home intervention team (HIT): Results from the randomized falls-HIT trial. J Am Geriatr Soc 2003;51:300-305.

31. Steinberg M, Cartwright C, Peel N et al. A sustainable programme to prevent falls and near falls in community dwelling older people: Results of a randomised trial. J Epidemiol Commun Health 2000;54:227-232.

32. Van Haastregt JC, Diederiks JP, van Rossum E et al. Effects of a programme of multifactorial home visits on falls and mobility impairments in elderly people at risk: Randomized controlled trial. BMJ 2000;321:994-998.

33. Vetter NJ, Lewis PA, Ford D. Can health visitors prevent fractures in elderly people? BMJ 1992;304:888-890.

34. Wagner EH, LaCroix AZ, Grothaus L et al. Preventing disability and falls in older adults: A population-based randomized trial. Am J Public Health 1994;84:1800-1806.

35. Whitehead C, Wundke R, Crotty M et al. Evidence-based clinical practice in falls prevention: A randomised controlled trial of a falls prevention service. Aust Health Rev 2003;26:88-97.

36. Hornbrook MC, Stevens VJ, Wingfield DJ et al. Preventing falls among community-dwelling older persons: Results from a randomized trial. Gerontologist 1994;34:16-23.

37. Kingston P, Jones M, Lally F et al. Older people and falls: A randomized controlled trial of a health visitor (HV) intervention. Rev Clin Gerontol 2001;11:209-214.

38. Rubenstein LZ, Robbins AS, Josephson KR et al. The value of assessing falls in an elderly population. Ann Intern Med 1990;113:308-316.

39. Leipzig RM, Cumming RG, Tinetti ME. Drugs and falls in older people: A systematic review and meta-analysis: I. Psychotropic drugs. J Am Geriatr Soc 1999;47:30-39.

40. Arfken CL, Wilson JG, Aronson SM. Retrospective review of selective serotonin reuptake inhibitors and falling in older nursing home residents. Int Psychogeriatr 2001;13:85-91.

41. Ensrud KE, Blackwell T, Mangione CM et al. Study of Osteoporotic Fractures Research Group. Central nervous system active medications and risk for fractures in older women. Arch Intern Med 2003;163:949-957.

42. Healey F, Monro A, Cockram A et al. Using targeted risk factor reduction to prevent falls in older in-patients: A randomized controlled trial. Age Ageing 2004;33:390-395.

43. Gardner MM, Robertson MC, Campbell AJ. Exercise in preventing falls and fall related injuries in older people: A review of randomised controlled trials. Br J Sports Med 2000;34:7-17.

44. Li F, Harmer P, Fisher KJ et al. Tai chi and fall reductions in older adults: A randomized controlled trial. J Gerontol A Biol Sci Med Sci 2005;60A: 187-194.

45. Liu-Ambrose T, Khan KM, Eng JJ et al. Balance confidence improves with resistance or agility training. Increase is not correlated with objective changes in fall risk and physical abilities. Gerontology 2004;50:373-382.

46. Lord SR, Castell S, Corcoran J et al. The effect of group exercise on physical functioning and falls in frail older people living in retirement villages: A randomized, controlled trial. J Am Geriatr Soc 2003;51:1685-1692.

47. Suzuki T, Kim H, Yoshida H et al. Randomized controlled trial of exercise intervention for the prevention of falls in community-dwelling elderly Japanese women. J Bone Miner Metab 2004;22:602-611. 
48. Wolf SL, Barnhart HX, Kutner NG et al. Reducing frailty and falls in older persons: An investigation of tai chi and computerized balance training. Atlanta FICSIT Group. Frailty and injuries: cooperative studies of intervention techniques. J Am Geriatr Soc 1996;44:489-497.

49. Foss AJ, Harwood RH, Osborn F et al. Falls and health status in elderly women following second eye cataract surgery: A randomised controlled trial. Age Ageing 2006;35:66-71.

50. Harwood RH, Foss AJ, Osborn MF et al. Falls and health status in elderly woman following first eye cataract surgery: A randomised controlled trial. $\mathrm{Br} \mathrm{J}$ Ophthalmol 2005;89:53-59.

51. Dyer CA, Taylor GJ, Reed M et al. Falls prevention in residential care homes: A randomised controlled trial. Age Ageing 2004;33:596-602.

52. Cumming RG, Ivers $R$, Clemson $L$ et al. Improving vision to prevent falls in frail older people: A randomized trial. J Am Geriatr Soc 2007;55:175-181.

53. Parry SW, Steen IN, Baptist M et al. Amnesia for loss of consciousness in carotid sinus syndrome: Implications for presentation with falls. J Am Coll Cardiol 2005;45:1840-1843.

54. Kenny RA, Richardson DA, Steen N et al. Carotid sinus syndrome: A modifiable risk factor for nonaccidental falls in older adults (SAFE PACE). J Am Coll Cardiol 2001;38:1491-1496.

55. Bischoff-Ferrari HA, Dawson-Hughes B, Willet WC et al. Effect of vitamin D on falls: A meta-analysis. JAMA 2004;28:291: 1999-2006. Review.

56. Bischoff-Ferrari HA, Dawson-Hughes B, Staehelin HB et al. Fall prevention with supplemental and active forms of vitamin D: A meta-analysis of randomised controlled trials. BMJ 2009;339:b3692. doi: 10.1136/bmj.b3692. Review.

57. Pfeifer M, Begerow B, Minne HW et al. Effects of a short-term vitamin D and calcium supplementation on body sway and secondary hyperparathyroidism in elderly women. J Bone Miner Res 2000;15:1113-1118.

58. Dukas L, Bischoff HA, Lindpaintner LS et al. Alfacalcidol reduces the number of fallers in a community-dwelling elderly population with a minimum calcium intake of more than $500 \mathrm{mg}$ daily. J Am Geriatr Soc 2004;52:230-236.

59. Gallagher EM. Elders in prison. Health and well-being of older inmates. Int J Law Psychiatry 2001;24:325-333.

60. Porthouse J, Cockayne S, King C et al. Randomised controlled trial of calcium and supplementation with cholecalciferol (vitamin D3) for prevention of fractures in primary care. BMJ 2005;330:1003.

61. Rubenstein LZ, Robbins AS, Schulman BL et al. Falls and instability in the elderly. J Am Geriatr Soc 1988;36:266-278.

62. Robbins S, Waked E, Krouglicof N. Improving balance. J Am Geriatr Soc 1998;46:1363-1370.

63. Lord SR, Bashford GM. Shoe characteristics and balance in older women. J Am Geriatr Soc 1996;44:429-433.

64. Arnadottir SA, Mercer VS. Effects of footwear on measurements of balance and gait in women between the ages of 65 and 93 years. Phys Ther 2000;51: 306-313.

65. Tencer AF, Koepsell TD, Wolf ME et al. Biomechanical properties of shoes and risk of falls in older adults. J Am Geriatr Soc 2004;52:1840-1846.

66. Lord SR, Tiedemann A, Chapman K et al. The effect of an individualized fall prevention program on fall risk and falls in older people: A randomized, controlled trial. J Am Geriatr Soc 2005;53:1296-1304.

67. Rucker D, Rowe BH, Johnson JA et al. Educational intervention to reduce falls and fear of falling in patients after fragility fracture: Results of a controlled pilot study. Prev Med 2006;42:316-319.

68. Cumming RG, Thomas M, Szonyi G et al. Home visits by an occupational therapist for assessment and modification of environmental hazards: A randomized trial of falls prevention. J Am Geriatr Soc 1999;47:1397-1402.

69. McKiernan FE. A simple gait-stabilizing device reduces outdoor falls and nonserious injurious falls in fall-prone older people during the winter. J Am Geriatr Soc 2005;53:943-947.

70. Stevens M, Holman CD, Bennett $\mathrm{N}$ et al. Preventing falls in older people: Outcome evaluation of a randomized controlled trial. J Am Geriatr Soc 2001;49:1448-1455.
71. Campbell AJ, Robertson MC, La Grow SJ et al. Randomised controlled trial of prevention of falls in people aged $>$ or $=75$ with severe visual impairment: The VIP trial. BMJ 2005;331:817.

72. Huang TT, Acton GJ. Effectiveness of home visit falls prevention strategy for Taiwanese community-dwelling elders: Randomized trial. Public Health Nurs 2004;21:247-256.

73. La Grow SJ, Robertson MC, Campbell AJ et al. Reducing hazard related falls in people 75 years and older with significant visual impairment: How did a successful program work? Inj Prev 2006;12:296-301.

74. Pardessus V, Puisieux F, Di Pompeo C et al. Benefits of home visits for falls and autonomy in the elderly: A randomized trial study. Am J Phys Med Rehabil 2002;81:247-252.

75. Brouwer BJ, Walker C, Rydahl SJ et al. Reducing fear of falling in seniors through education and activity programs: A randomized trial. J Am Geriatr Soc 2003;51:829-834.

76. Becker C, Kron M, Lindemann U et al. Effectiveness of a multifaceted intervention on falls in nursing home residents. J Am Geriatr Soc 2003;51: 306-313.

77. Oliver D, Connelly JBL, Victor CR et al. Strategies to prevent falls and fractures in hospitals and care homes and effect of cognitive impairment: Systematic review and meta-analyses. BMJ 2007;334:82.

78. Jensen J, Lundin-Olsson L, Nyberg L et al. Falls among frail older people in residential care. Scand J Public Health 2002;30:54-61.

79. Ray WA, Taylor JA, Meador KG et al. A randomized trial of a consultation service to reduce falls in nursing homes. JAMA 1997;278:557-562.

80. Kerse N, Butler M, Robinson E et al. Wearing slippers, falls and injury in residential care. Aust N Z J Public Health 2004;28:180-187.

81. McMurdo ME, Millar AM, Daly F. A randomized controlled trial of fall prevention strategies in old peoples' homes. Gerontology 2000;46:83-87.

82. Shaw FE, Bond J, Richardson DA et al. Multifactorial intervention after a fall in older people with cognitive impairment and dementia presenting to the accident and emergency department: Randomised controlled trial. BMJ 2003;326:73.

83. Jensen J, Nyberg L, Gustafson Y et al. Fall and injury prevention in residentia care-effects in residents with higher and lower levels of cognition. J Am Geriatr Soc 2003;51:627-635.

84. Rosendahl E, Gustafson Y, Nordin E et al. A randomized controlled trial of fall prevention by a high-intensity functional exercise program for older people living in residential care facilities. Aging Clin Exp Res 2008;20: 67-75.

85. Faber MJ, Bosscher RJ, Chin A Paw MJ et al. Effects of exercise programs on falls and mobility in frail and pre-frail older adults: A multicenter randomized controlled trial. Arch Phys Med Rehabil 2006;87:885-896.

86. Norwalk MP, Prendergast JM, Bayles CM et al. A randomized trial of exercise programs among older individuals living in two long term care facilities: The FallsFREE Program. J Am Geriatr Soc 2001;49:859-865.

87. Schoenfelder DP, Rubenstein LM. An exercise program to improve fall-related outcomes in elderly nursing home residents. Appl Nurs Res 2004;17:21-31.

88. Shimada H, Obuchi S, Furuna $\mathrm{T}$ et al. New intervention program for preventing falls among frail elderly people. The effects of perturbed walking exercise using a bilateral separated treadmill. Am J Phys Med Rehabil 2004;83:493-499.

89. Wolf SL, Sattin RW, Kutner M et al. Intense tai chi exercise training and fall occurrences in older, transitionally frail adults: A randomized controlled trial. J Am Geriatr Soc 2003;51:1693-1701.

90. Flicker L, MacInnis RJ, Stein MS et al. Should older people in residential care receive vitamin $\mathrm{D}$ to prevent falls? Results of a randomized trial. J Am Geriatr Soc 2005;53:1881-1888.

91. Broe KE, Chen TC, Weinberg J et al. A higher dose of vitamin d reduces the risk of falls in nursing home residents: A randomized, multiple-dose study. J Am Geriatr Soc 2007;55:234-239.

92. van Dijk PT, Meulenberg OG, van de Sande HJ et al. Falls in dementia patients. Gerontologist 1993;33:200-204. 